\title{
Abused Women's Perceptions of Professionals' Responses: Valued Support, or Collusion With Perpetrator?
}

\section{To cite this paper:}

Neale, J. (2018). Abused Women's Perceptions of Professionals' Responses: Valued Support, or Collusion With Perpetrator? Journal of Gender-Based Violence, 2 (3), <pages>

\begin{abstract}
:
Domestic violence and abuse (DVA) is recognised as a serious public health issue that detrimentally affects the lives of victims during, and after exiting, the relationship. For staff in overstretched criminal justice, health and social care agencies, high prevalence rates of DVA place a significant strain on the financial and emotional resources available to them. Drawing on Angie Ash's (2013) concept of 'cognitive masks', and using data collected as part of a larger study, I examine the responses from agencies that frustrated women's attempts to leave an abusive male partner. Fourteen women, recruited via three specialist support agencies in two English counties and my own personal networks, participated in semi-structured narrative style interviews. Findings suggest that practitioners sometimes ignore significant aspects of the case, thus rendering the situation more manageable - for themselves. For women, however, this can frustrate their attempts to exit the relationship and remain abuse-free.
\end{abstract}

\section{Introduction}

Domestic violence and abuse (DVA) is now recognised as a serious public health issue that detrimentally affects the lives of women during, and long after exiting, the relationship. Violence can result in long-term problems with their physical health (Ferreira et al. 2015; Wong and Mellor 2014), sexual health (Williams et al. 2010; Wong and Mellor 2014), and mental health (Hegarty et al. 2013; Karakurt et al. 2014). It also has a substantial impact on emotional wellbeing. It has been shown to lead to psychosocial problems such as fearfulness, depression and PTSD, anxiety attacks, sleeping problems, low self-esteem, feelings of shame and guilt, difficulties in building and maintaining relationships (Skomorovsky et al. 2015; Stockman et al. 2015) and significantly reduced quality of life (Wittenberg et al. 2007). Women who have been abused experience difficulty making decisions, and in trusting themselves and others; it undermines their confidence and sense of self-efficacy, and engenders feelings of worthlessness (Abrahams 2010).

There are also significant financial implications from the harm caused by domestic abuse. In the UK, the cost is conservatively estimated to be nearly $f 16$ billion per year. This includes $f 10$ billion in human suffering, the cost to employers of $f 1.9$ billion, and the cost to the state (of providing physical and mental health care, social services, housing, criminal justice and civil legal services) of $£ 3.8$ billion (Walby 2009).

In addition, DVA is closely associated with other crimes. Domestic violence accounts for $14 \%$ of all violent crime in England and Wales (Home Office 2010), and has a higher rate of repeat victimisation than any other crime (Walby and Allen 2004). In psychiatric populations, a third of female patients had experienced domestic violence (Oram et al. 2013), and in Brandon et al's (2012) study of 139 serious case reviews in the UK (where there had been the death or serious injury of a child), domestic abuse featured in nearly two-thirds of cases. Thus, for staff in already overstretched criminal justice, health and social care agencies it places a significant strain on the financial and emotional resources available to them. 
The agencies with which women come into contact are obliged to provide a person-centred, integrated service [see, for example, the International Commission of Jurists' (2016) Practitioners' Guide; The National Institute for Health and Care Excellence (NICE, 2016) Domestic Violence and Abuse Quality Standard; and the Home Office's (2016) Violence Against Women and Girls Statement of Expectations]. However, because there is no effective monitoring of agencies' adherence to these guidelines (Jacob, 2017), women do not always receive the level or quality of service to which they have a right.

Despite irrefutable research evidence showing that its services are effective, and that independent advocacy is what women want (Centre for Gender and Violence Research, 2018), over the last two decades there has been a noticeable shift in the specialist women's sector in the UK. What was once a significant source of support for individual women experiencing DVA (and a political movement for social change) has been reduced to, apart from a few notable exceptions, the provision of depoliticised and clinicalised services (Lehrner and Allen, 2009, McDonald, 2005). In the more recent climate of swingeing budget cuts (Grierson, 2018) and the move toward competitive funding for refuges and other women's services, the basic feminist principles that, from the 1970s, underpinned the UK women's sector have largely been eroded. The demands of local authority funders for more heavily regulated voluntary sector services and high 'outputs' (measured in terms of the numbers of women receiving a service rather than its quality), has compromised those services' ability to respond appropriately to the range and complexity of needs with which women present (Warrington, 2003). In a more recent response to this climate, Women's Aid Federation of England has developed a whole community approach to service delivery, 'Change that Lasts'. The model includes trained 'ask me ambassadors' based in the community, 'trusted professionals' in frontline services and 'expert support' from specialist domestic abuse services. Together, these schemes provide 'a framework that facilitates the shortest, and/or most effective route to safety, freedom and independence for each survivor' (WAFE, 2017). It is an evidence-based approach that aims to regain, and further develop, the ground lost in recent years.

This paper is drawn from data collected as part of my $\mathrm{PhD}$ research, the aim of which was to explore the processes by which heterosexual women enter, endure and leave abusive relationships. One of the more significant themes to have emerged from participants' narratives is the ways in which services can facilitate or hinder women's attempts to escape the abuse. There are many accounts in participants' stories of really helpful interventions by the agencies with which they came into contact. However, the impact of these is easily undermined by other, less considered, responses. In this paper I explore the responses from agencies that served to frustrate a woman's attempts to leave an abusive partner, and what they might mean for her sense of identity.

Drawing on Julia Kristeva's (1982) work, in which 'abjection' is understood to be a psychological defence against anything that threatens one's sense of self, Bradbury-Jones and Taylor (2013) explore nurses' inappropriate responses to domestic abuse. They propose that some nurses subconsciously reject domestic abuse as a possible factor in the presenting symptoms of patients because it transgresses established social boundaries of what is considered to be nurses' 'clean and proper' self. Implicit in Bradbury-Jones and Taylor's argument is that the perceived threat to self has been recognised, at some intrapsychic level; having become aware of it, some nurses react to avoid it. I am suggesting that, for some frontline staff, this protection of self takes place before the threat is even encountered. In the following section I draw on the work of Michael Lipsky (1980) and Angie Ash (2013) to suggest that the less helpful responses from front line staff result from their attempts to manage the pressure of doing this work. I am applying the notion of 'cognitive masks' (Ash 2013) being used as a way in which professionals occlude, or shut out, the more troublesome facets of the cases with which they are dealing. 


\section{Street Level Bureaucracy}

Michael Lipsky (1980) argues that state employees such as teachers, police officers and social workers are the people who meet citizens at the interface between citizens and government, and actually implement the policy that has been constructed elsewhere. They should, therefore, be seen as part of the policy-making community, and as exercisers of political power. Frontline workers in public sector agencies, Lipsky's 'street-level bureaucrats', consider that they are doing the best they can, given the constraints (limited time and resources, agency policy and rules) within which they are working and the dilemmas that these give rise to. The tension between maintaining one's core values (i.e. working to the highest standards of decision making) and operating under such conditions leads to cognitive dissonance - a psychological state in which two or more conflicting beliefs are held simultaneously. Through individual acts of discretion, and by protecting themselves with 'cognitive shields' (for example, by rationing services, or constructing the client as 'blameworthy'), this dissonance is rendered manageable by workers.

...the decisions of street level bureaucrats, the routines they establish, and the devices they invent to cope with uncertainties and work pressures, effectively become the public policies they carry out (Lipsky 1980).

Lipsky's theory is now well established, and has been applied across a range of public sector areas including social care (Carson et al. 2015; Ellis 2014; Goldman and Foldy 2015; Scourfield 2015), health (Hughes and Condon 2016; Tummers et al. 2015), education (Barberis and Buchowicz 2015; Newton 2002; Taylor 2007), policing and probation (Buvik 2016; Wooditch et al. 2016), and public administration (Baker Collins 2016; Dorch 2009; Zang 2016). Angie Ash (2013), however, in her study of the constraints on social workers when implementing policy to protect older people from abuse, suggests that Lipsky's notion of 'shield' with its imputation of solidity and impermeability is somewhat crude. She favours the metaphor of 'cognitive masks', and notes:

As a fencing mask both protects and partially obscures, cognitive masks closed down taking a sharp, clear, wide-angle view to ask why those dilemmas existed (Ash 2013).

In his typology of domestic violence, Michael Johnson (2008) distinguishes between: 'intimate terrorism', in which the perpetrator uses violence as merely one tactic in a general pattern of oppressive behaviours; 'situational couple violence', in which both partners in a relationship may resort to violence within the context of a specific argument, 'violent resistance', which involves one partner reacting with violence to abuse from the other; and 'mutual violent control', a form of mutual combat in which two intimate terrorists battle for control. For women experiencing intimate terrorism, the UK Government definition of domestic violence and abuse has significant implications. In conflating intimate terrorism with other forms of intimate partner abuse, it provides possibilities for professionals under pressure (i.e. street level bureaucrats) to regard victims as at least partly responsible for their experiences.

\section{Methodology}

\section{Context for the study and research approach}

Two major aims for feminist researchers and activists are to challenge the dominant representations of violence against women and girls that reproduce systemic gender inequality and to privilege the voices of those previously silenced. I am resisting, and arguing for an alternative to, the traditional view in which the 'problem' is located within individuals (i.e. certain people perpetrate, invite another to perpetrate, or do not do enough to prevent/resist domestic abuse). I suggest this leads to: the pathologisation of individuals; a stunting simplification of the problem(s) and the solution(s); and narrows the range of understanding. Instead I am arguing that structural inequalities restrict women's 'space for action' (Kelly 2005), thus limiting the choices available to them. 


\section{Participants}

A purposive sampling strategy (Silverman 2013) was adopted, in that participants were selected on the basis of their relevance to the research question and, as such, my theoretical position - rather than being representative of any given group. Participants were women who had experienced DVA. They were recruited via three agencies in Bedfordshire and Hertfordshire (England) that provide specialist DVA services for women, and from my own professional networks.

Fourteen women participated in the study. They ranged in terms of socioeconomic status (high, middle and low), age (from mid-twenties to late-forties), and ethnicity (African Caribbean, Black African, South Asian, White British and White European backgrounds).

\section{Data collection and analysis}

In order to facilitate a validation of participants' subjective experiences (Oakley 1981), narrative-style interviews were used to collect data. In this method, the interviewee is positioned as 'storyteller', and is responsible for clarifying the meaning of what is being said (Greenspan 1998). The story is seen as a co-construction between the interviewee and the interviewer. This approach, rather than one that imposes an a priori researcher-led focus on the interview, allows participants to disclose the aspects of their experiences that are most meaningful for them.

Interviews were recorded using a digital voice recorder. Hand written notes were also made. Audio files and hand-written notes were uploaded on to a personal computer. Interviews were transcribed, coded and analysed using Braun and Clarke's (2006) method of thematic analysis. This method allows for an analysis that goes beyond the individual's account, and an exploration of the ways in which it might be influenced by factors outside of the narrative provided. Using this method enabled me to look at women's accounts of entering, enduring and leaving relationships with abusive partners, and explore the ways in which their experiences and understandings might have been shaped by, for example, the behaviour of others. Themes identified in the data included 'first encounters and courtship', 'living with abuse', and 'leaving'. One of the sub-themes in the last of these, 'interventions by others', was further sub-divided in to 'family and friends' and 'professionals'. The focus of this paper is my analysis of participants' accounts of interventions by professionals.

\section{Ethics}

Central, secure, and inconspicuous venues were used for the interviews, and informed consent was sought from each participant. Confidentiality and anonymity (pseudonyms are used throughout) were assured, and no information about them was sought from any other source. Any participant requiring support was provided with information about the services offered by relevant local agencies, and encouraged to contact them. Participants were provided with a copy of their transcribed interviews, and have been fully consulted and informed as to how their accounts would be used. Ethical approval for the project was granted by the University of Bedfordshire's Research Ethics Committee.

The data consist of 43 hours of recorded interview with 14 women, collected between June 2011 and May 2014.

\section{Findings}

Participants had all managed to separate from their abusing partner, and their stories contain many accounts of agency interventions that helped them to do so. However, the more positive interventions can be easily undermined, and even sabotaged completely, by less considered responses from professionals. I propose that, in order to manage the cognitive dissonance arising from this work, practitioners use their discretion in selecting which parts of the situation they attend to. In the following examples, street level bureaucrats across a range of agencies occluded either the main storyline (i.e. DVA) or one of its key characters. 


\section{Occlusion of DVA}

Of the fourteen participants, two had managed to exit the relationship independently, and a third woman had done so with support from a voluntary organisation but had not been in contact with any statutory agencies. Each of the remaining eleven participants gave accounts in which they felt that domestic abuse was 'not on the radar' of some of the professionals with whom they came into contact. In some cases, this led to a medical diagnosis ('depression', for example) based on the symptoms of their distress, but little or no support in dealing with the root cause. For example, Marcia's inability to see any other escape from her violent and abusive husband had led her to attempt suicide. She had taken an overdose, and was admitted to hospital. She recalled, with some discomfort, the response she received from the psychiatrist and nursing staff:

...I can remember coming to and the rough treatment the nurses were giving and the way they were speaking about me above me, just so awful, really awful, yeah, derogatory comments, no care or compassion whatsoever (Marcia).

Whilst she was being treated, Marcia's husband had not left her side. When they were alone together, he threatened further violence if she disclosed his abuse. A psychiatrist assessed and, eventually, discharged her without ever having spoken to her alone.

In Marcia's view, the response that she had received from the health professionals had been extremely insensitive and uncaring. She felt let down by their lack of consideration - both of her emotionally fragile state, and their lack of professional curiosity about what had triggered her suicide attempt.

...and there I was, twenty-one and that was the help I was getting, I mean what more signs do you need? (Marcia).

Her thoughts were that the staff had colluded with him, albeit inadvertently; she was discredited as an hysterical, selfish and attention-seeking woman, whilst he was cast as 'heroic carer' (Thiara et al. 2012) and thus remained in complete control.

A further example was provided by Kamala. She had been subjected to her husband's physical and emotional abuse throughout her marriage, and had required hospital treatment for her injuries on many occasions. Later on in their relationship, he began forcing her to have sex with his friends and other men. Perhaps unsurprisingly, she had required treatment for sexually transmitted infections (STIs) at her local Genito-Urinary Medicine (GUM) Clinic. As had Marcia, Kamala interpreted her clinician's response toward her as one of contempt:

...and I thought the woman's looking at me as if to say, "Well what do you actually do?" Surely you'd think once, "Is someone abusing you?" or, "Are people abusing you?" more to the point, you know? They don't ask questions (Kamala).

Like Marcia, Kamala wanted to be asked about the reasons behind her contact with health professionals. Most women who are being abused will not offer this information up voluntarily (Bacchus et al. 2002), but routine screening in healthcare settings has been shown to have a significant positive impact on the rates of disclosure (Litherland 2012). There are clear benefits to routine enquiry; it helps to reduce the stigma associated with being a victim, and disclosure presents an opportunity to put women in contact with support services (Allen et al. 2007; Buck and Collins 2007; Spangaro et al. 2011). Despite this, inappropriate responses from healthcare professionals have been widely documented in the literature. For example, factors found to be barriers to routine screening in healthcare settings include: lack of knowledge about DVA; lack of skill in asking about it; fear of offending patients by asking them about it; perceived time pressures; a perception that DVA is outside the purview of their work; victim-blaming attitudes toward DVA; and fear of loss of control of the provider-patient relationship (Bradbury-Jones and Taylor 2013; Hamberger and Phelan 2006). 
Kamala felt that she had been judged by the GUM clinic health professional to be sexually promiscuous, and therefore responsible for contracting STIs. Seemingly, the possibility that both she and Marcia were, in fact, victims of extreme and escalating violence and abuse had not been considered. This left them feeling blamed for their own predicaments (and for wasting scarce public resources needed to treat 'more deserving' cases), and unable to access information and advice on how to escape. As these two examples show, it is imperative that staff working in settings such as these are prepared to countenance the possibility of, and are trained to enquire about and respond appropriately to, domestic abuse.

\section{Occlusion of perpetrator}

When reacting to requests for help from victims of DVA frontline workers, on occasions, seemed to participants to manage their cognitive dissonance by occluding the perpetrator. In these cases, the focus was shifted from the root of the problem (i.e. the perpetrator's behaviour) to his victim's response. The form that this took involved blaming her for the continuing abuse and/or holding her responsible for managing it.

Kirsten recalled an occasion when her husband had broken the terms of a court order, and was 'hammering' on the door to the flat that she and her children were occupying. Eventually, so distressed by the effect that this was having on their children, and concerned about the disturbance to her neighbours, she opened the door; she was then assaulted by him. The police attended, and arrested him - but one of the officers suggested to her that she was to blame for the assault because she had opened the door to him. In foregrounding Kirsten's (re)actions this officer had failed to 'see' the perpetrator as the catalyst, and the effect that his actions would have had on Kirsten and her children.

Leonie had asked the police to intervene to prevent her husband's abuse on more than one occasion. The violence to which she had been subjected included, for example, having a microwave oven thrown at her - which had smashed on the floor next to her. In his frustration at having missed his target he then kicked a Moses basket, occupied by their baby, across the room.

When we met, Leonie had part-time contracts with two different employers, and was energetically seeking full-time employment. She had registered, and was in regular contact, with several specialist employment agencies. She had separated from her abusive husband, and had managed to keep her address a secret from him. This had clearly incensed him, and she had received dozens of emails, text messages and telephone calls in which he had threatened to kill her and their child. The police response was that there was not much they could do:

...because they said it wasn't physical, ... and they told me to change my email, and change my phone (Leonie).

In Leonie's resulting world view, the police saw the problem as the ugly messages that she was receiving - not the person sending them; thus, she was expected to take responsibility for negating the impact of her husband's behaviour. Because of their inaction, Leonie was forced to choose between risking loss of contact with prospective employers (and other peripheral acquaintances) and preventing her ex-husband from terrorising her. She returned to this theme later in our conversation.

I told them I said, "Dead men don't talk, if I die today", there's no way they can know what has been going on, or what happened, it's only assumption, they can only assume that OK this has all happened probably the man came into the house, and hit her and killed her (Leonie).

Leonie's concern is not without foundation. Police failings have been noted in the domestic homicides of at least ten women since 2008 (BBC 2014; Churchill and Davenport 2014; Guardian 2013; IPCC 2010; IPCC 2012a; IPCC 2012b; IPCC 2013a; IPCC 2013b; IPCC 2014; Taylor 2011). Based on the fact that she was in fear, the police were in a position to have carried out a Domestic Abuse and Stalking (DASH 2009) risk assessment, and investigate Leonie's claims. His behaviour represented offences against the Offences Against the Person Act (1861), Malicious Communications Act (1988), and the Protection 
from Harassment Act (1997). Leonie felt that their inaction left her powerless to do anything other than record the incidents, to be used only in the event that her ex-husband carry out his threats.

Social workers also appeared to occlude the perpetrator by foregrounding, and then blaming, the victim. Other authors have noted children's services social workers' reluctance to work with perpetrators (Featherstone 2003; Littlechild 2008; Maxwell et al. 2012). The 'invisibility' of violent fathers leads to mother-blaming, and mothers then become the focus of assessment, monitoring and intervention procedures (Humphreys and Absler 2011; Stanley 1997).

Kim and Kirsten both gave accounts in which they felt 'discredited' (Goffman 1963) by virtue of their experiences of abuse. For example, Kim noted:

...you're always trying to sort of make sure that you're not viewed in a certain way, because this has happened in your household, through no fault of your own, ....'cos it is like they do put you in a box (Kim).

She went on to describe a visit from her children's social worker:

... when she first came round it was like she'd already stereotyped us as oh um a large family, mixed race children, domestic violence, ...living in a council house [a form of social housing in the UK], in a pretty run-down area (Kim).

The social worker had insisted that Kim attend a domestic violence programme and it was this that had increased her ability to articulate her thoughts and feelings. In her view, the programme:

...builds up your confidence and takes you out of the mindset that you are in, when you're in that relationship, ... and makes you see it, from outside of it, and that, you know what? The man's just got issues, end of, ... when he goes to another relationship it's going to be exactly the same, you know, because it is him, it's not the woman (Kim).

It is ironic that the social worker's insistence on the programme had helped Kim to locate responsibility for the abuse firmly with the perpetrator, yet she still felt positioned by her as blameworthy.

Kirsten had been physically assaulted by her husband on a number of occasions. Because of his violence, she and their children had spent short periods of time in a refuge. She was acutely aware of the trauma and disruption that they were experiencing but described being made, by her children's social worker, to feel as though she alone was responsible for their distress:

...it feels like you're the perpetrator, like you're the one in the wrong (Kirsten).

When she tried to foreground her husband's responsibility, she was told:

... "Well you chose this man you chose to stay with him and you chose to have children with him knowing what he was like. Why would you do that?" (Kirsten).

Kirsten attempted to resist being positioned as 'blameworthy' by stating that he had not been violent in the earlier stages of their relationship. She was then told that she must be doing something to trigger his violence, and described the social worker's response:

... "Oh but you know he's so lovely and he's very good looking and, you know he comes from a good family and you're the one who comes from a dysfunctional home, clearly you're the problem" (Kirsten).

This tendency to hold victims responsible for their circumstances was not uncommon. Of the eleven participants who had contact with statutory agencies, eight gave examples in which the perpetrator seemed to them to be occluded by professionals. By ignoring the source of women's difficulties, frontline workers effectively distil the problem into something that is more manageable - for them. Occluding the perpetrator renders the situation, and practitioners' responses to it, simpler and safer. For victims, however, this merely increases their sense of isolation; they feel criticised, and overwhelmed by the expectations it makes of them. 


\section{Occlusion of victim}

Another way in which practitioners appeared to manage cognitive dissonance was by losing sight of the victim. This left women feeling ambivalent about professionals' ability to help them. Of the eleven who had contact with statutory agencies, six participants described having felt somewhat invisible to professionals. The form this took most often involved a failure to keep women abreast of developments with their cases. For example, Nombeko's understanding was that the police were pursuing two separate cases against her husband - one for raping her, and the other for knowingly infecting her with HIV (Grievous Bodily Harm). She commented:

...they promised to give me monthly updates and they haven't given me monthly updates, and I've phoned a few times to try and speak to the investigating detective, and most of the times he's either not in the office, and he's going to be given a message to call me, and I never get a message from him (Nombeko).

Another participant talked about the way in which she and her daughter were made to feel when HM Courts and Tribunals Service (HMCTS) undermined the strenuous efforts of the police to hold her abuser accountable for his behaviour:

...the police said, "You don't have to say whether you want to press charges 'cos we can take it out of your hands", and they said and "Don't worry" he said "because we make it plain to him that we are pressing charges not you", because had it been me, more resentment, so yeah they took it out of my hands which I obviously was so grateful for, ... they prosecuted him yeah (Eve).

Eve had spoken in extremely positive terms about the help she had received - right up until the point where she and her daughter had been asked for their permission to write off her husband's compensation.

...this is the part that really annoyed me, he got a fine, for what he done to me and my daughter, he made one payment, it was like about two pound something, ...didn't pay the rest, we got a letter to say that you know it's not likely that he's going to pay it, can you just write it off? (Eve).

Much of the hard work carried out by the police, in taking forward a 'victimless prosecution', was thus undermined by the action of HMCTS. In Eve's view, for HMCTS it was simply an accounting problem, a 'bad debt' to be written off; she and her daughter, and the experiences for which they were being compensated, were irrelevant. Eve felt that, had they agreed to the request, her husband's behaviour would have, ultimately, held no consequences for him. She commented:

I was like, "Not a chance, not a chance, even if I never get the money I ain't never going to write that off". I thought, "How dare they, so they're covering for him now" (Eve).

These findings indicate some of the ways in which street-level bureaucrats manage the cognitive dissonance they experience when working with domestic abuse. In the examples presented above, it appears that the abuse itself, the perpetrator, or his victim, was occluded. In the next section I discuss what this might mean for women attempting to escape an abusive partner.

\section{Discussion}

Celia Kitzinger (1994) refers to society's tendency to minimise the seriousness of violence against women as 'the frequency game'. She claims that a 'taken for granted' understanding dictates that 'if it's rare, it's not a problem; if it's common, then it is normal rather than problematic.' DVA is far from rare - and places a significant strain on public sector services. Angie Ash suggests that:

The place at which the commonplace meets pressure on resources is a pinch point where dissonance sets in, expectations are lowered and cognitive masks are forged (Ash 2013). 
There is a tension between working and, for that matter, publishing in 'silos' (policing/criminal justice, social work, health, etc.) and the need to recognise that women are in contact with a wide range of agencies. As previously stated, participants gave many examples of professionals from various agencies 'going the extra mile', and they were keen to stress the significance of these interventions in helping them to exit the relationship. However, a chain is only as strong as its weakest link, and the purpose of this paper is to discuss the behaviours that undermined women's ability to end their abuse. When contemplating their chances of escaping the abuse, they do not evaluate one service in isolation; they 'stress test' the entire chain and, if it fails, care little about where exactly it does so.

In considering what her husband had inferred from agency responses to his behaviour, Nombeko articulated the frustrations of many participants:

...he thinks he's got away with everything, he basically will say things like, "Well, you even went to the police, you thought you were going to get me in trouble, they didn't believe what you said", you know, so he's going around thinking, "I can get away with this, I've got away with many things before, and I've got away with this one", and, to some extent I sort of felt, ....he is not going to learn, if he thinks he can keep getting away with things, it means he's going to keep doing it and doing it and doing it (Nombeko).

Given that less than a third of domestic abuse perpetrators receive a community or custodial sentence (Centre for Gender and Violence Research, 2018; On Track 2017), Nombeko's concern would appear justified. When professionals occlude either the abuse itself or the individual responsible, they clear the way for the behaviour of that individual to continue unchecked. The message that perpetrators receive is that, for them, their actions hold no consequences.

As mentioned earlier, the emotional impact of DVA on victims is significant and enduring. The various strategies used by perpetrators to control their victims combine to damage their sense of self-efficacy and self-worth. Women can find it hard to make even simple decisions, and have difficulty in trusting anyone (Abrahams 2007; Abrahams 2010). The examples presented here suggest that, when domestic abuse or those who perpetrate it are occluded by frontline practitioners, women feel blamed by them for the circumstances in which they find themselves. When the victim is occluded and, by implication, her experiences of abuse unacknowledged, this is perceived by women to reinforce the feelings of worthlessness cultivated by their abusers. In the absence of a "sharp, clear, wide-angle view" (Ash 2013), practitioners respond inappropriately to the situation which, in turn, leaves women feeling pathologised, unsupported, and trapped in the relationship.

Whilst the policy within which services operate may be designed to help women to escape the abuse, this aim can be easily subverted by those responsible for implementing that policy. The use of cognitive masks by frontline practitioners leads to 'social entrapment' (Whiting 2013), and has the effect of reinforcing the perpetrator's strategies for isolating his victim. Women experiencing DVA see clearly the issues that street-level bureaucrats occlude; they perceive this tendency to avoid a wideangled view as collusion with the perpetrator. Thus, for them, occlusion and collusion are two faces of the same coin.

\section{Conclusion}

The aim of this article was to examine, in a way that does not pathologise individuals, the responses from statutory agencies that frustrated women's attempts to leave abusive male partners. The small sample size in my study limits the extent to which conclusions can be generalised to a wider population, but the findings are in line with previous research. Participants' accounts suggest that, despite national guidelines on person-centred care (Home Office, 2016, International Commission of Jurists, 2016, NICE, 2016), practitioners in statutory agencies sometimes ignore significant aspects of the case, thus rendering the situation more manageable - for themselves. For women, however, this can frustrate their attempts to exit the relationship and remain abuse-free. 
In order to improve women's chances of achieving safety, three issues need to be addressed. Firstly, the barriers to screening for DVA, particularly in healthcare settings, must be removed. This would increase the opportunities for women to disclose their experiences of abuse, and access support. Secondly, women's advocacy services must be restored and, ideally, further developed. The model favoured by Women's Aid, 'Change that Lasts', is evidence-based, cost-effective and preferred by women experiencing abuse (WAFE, 2017). However, its effectiveness is dependent on it being underpinned by a secure and sustainable specialist women's sector. Finally, training for professionals working directly with those experiencing DVA needs to be routine, and firmly embedded in their continuing professional development. Lipsky's (1980) and Ash's (2013) work would be useful in such training, because it acknowledges the pressures and constraints on 'Street Level Bureaucrats' when responding to this form of abuse. It offers a critical lens through which to examine such practices in a way that does not pathologise practitioners. An improved understanding of these processes, and their impact on women experiencing domestic abuse, could enable more effective practice responses.

\section{References}

(1861). Offences Against the Person Act, United Kingdom.

(1988). Malicious Communications Act, United Kingdom.

(1997). Protection from Harassment Act, United Kingdom.

Abrahams, H. (2007). Supporting Women After Domestic Violence: Loss, Trauma and Recovery, London: Jessica Kingsley.

Abrahams, H. (2010). Rebuilding Lives After Domestic Violence: Understanding Long-Term Outcomes, London: Jessica Kingsley.

Allen, N. E., Lehrner, A., Mattison, E., Miles, T., and Russell, A. (2007). "Promoting systems change in the health care response to domestic violence." Journal of Community Psychology, 35(1), 103-120.

Ash, A. (2013). "A Cognitive Mask? Camouflaging Dilemmas in Street-Level Policy Implementation to Safeguard Older People from Abuse." British Journal of Social Work, 43(1), 99-115.

Bacchus, L., Mezey, G., and Bewley, S. (2002). "Women's perceptions and experiences of routine enquiry for domestic violence in a maternity service." BJOG: An International Journal of Obstetrics \& Gynaecology, 109(1), 9-16 8p.

Baker Collins, S. (2016). "The Space in the Rules: Bureaucratic Discretion in the Administration of Ontario Works." Social Policy and Society, 15(2), 221-235.

Barberis, E., and Buchowicz, I. (2015). "Creating Accessibility to Education: The Role of School Staff's Discretionary Practices." European Education, 47(1), 61-76.

BBC. (2014). "Linah Keza death: Stabbed model told police she was 'petrified' of boyfriend". City.

Bradbury-Jones, C., and Taylor, J. (2013). "Domestic abuse as a transgressive practice: understanding nurses' responses through the lens of abjection." Nursing Philosophy: An International Journal For Healthcare Professionals, 14(4), 295-304.

Brandon, M., Sidebotham, P., Bailey, S., Belderson, P., Hawley, C., Ellis, C., and Megson, M. (2012). New Learning from Serious Case Reviews: a Two Year Report for 2009-2011. Department for Education, London.

Braun, V., and Clarke, V. (2006). "Using thematic analysis in psychology." Qualitative Research in Psychology, 3(2), 77-101.

Buck, L., and Collins, S. (2007). "Why don't midwives ask about domestic abuse?" British Journal of Midwifery, 15(12), 753-758.

Buvik, K. (2016). "The hole in the doughnut: a study of police discretion in a nightlife setting." Policing \& Society, 26(7), 771-788.

Carson, E., Chung, D., and Evans, T. (2015). "Complexities of discretion in social services in the third sector." European Journal of Social Work, 18(2), 167-184. 
Centre for Gender and Violence Research. Justice, Inequality and Gender Based Violence Conference. 15 May 2018 University of Bristol.

Churchill, D., and Davenport, J. (2014). "Hackney murders: IPCC investigating after mother 'complained of domestic violence'"Evening Standard. City: London.

DASH. (2009). Domestic Abuse, Stalking and Honour Based Violence Risk Identification, Assessment and Management Model.

Dorch, E. L. (2009). "The Implications of Policy Pre-Post Test Scores For Street-Level Bureaucratic Discretion." Journal of Health \& Human Services Administration, 32(2), 141-165.

Ellis, K. (2014). "Professional Discretion and Adult Social Work: Exploring Its Nature and Scope on the Front Line of Personalisation." British Journal of Social Work, 44(8), 2272-2289.

Featherstone, B. (2003). "Taking Fathers Seriously." British Journal of Social Work, 33(2), 239-254.

Ferreira, M. d. F., Moraes, C. L. d., Reichenheim, M. E., Verly Junior, E., Marques, E. S., and SallesCosta, R. (2015). "Effect of physical intimate partner violence on body mass index in lowincome adult women." Cadernos De Saúde Pública, 31(1), 161-172.

Goffman, E. (1963). Stigma: notes on the management of spoiled identity, London: Penguin.

Goldman, L. S., and Foldy, E. G. (2015). "The Space before Action: The Role of Peer Discussion Groups in Frontline Service Provision." Social Service Review, 89(1), 166-202.

Greenspan, H. (1998). On Listening to Holocaust Survivors: Recounting and Life History, Westport, CT: Praeger.

Grierson, J. 2018. Council funding for women's refuges cut by nearly $\mathrm{f} 7 \mathrm{~m}$ since 2010 . The Guardian, p.23 March.

Guardian. (2013). "Rachael Slack inquest: police failings contributed to deaths, jury finds"The Guardian. City: Guardian Media Group: London.

Hamberger, L. K., and Phelan, M. B. (2006). "Domestic violence screening in medical and mental health care settings: overcoming barriers to screening, identifying, and helping partner violence victims." Journal of Aggression, Maltreatment \& Trauma, 13(3-4), 61-99.

Hegarty, K., O'Doherty, L., Chondros, P., Valpied, J., Taft, A., Astbury, J., Brown, S., Gold, L., Taket, A., Feder, G., and Gunn, J. (2013). "Effect of Type and Severity of Intimate Partner Violence on Women's Health and Service Use." Journal of Interpersonal Violence, 28(2), 273-294.

Home Office. (2010). Crime in England and Wales 2009/10: Findings from the British Crime Survey and Police Recorded Crime (Third Edition), London: Home Office.

Home Office. (2016). Violence Against Women and Girls: National Statement of Expectations. London: Home Office.

Hughes, A., and Condon, L. (2016). "Street-level bureaucracy and policy implementation in community public health nursing: a qualitative study of the experiences of student and novice health visitors." Primary Health Care Research and Development, 17(6), 586-598.

Humphreys, C., and Absler, D. (2011). "History repeating: child protection responses to domestic violence." Child \& Family Social Work, 16(4), 464-473.

International Commission of Jurists 2016. Women's Access to Justice for Gender-Based Violence: A Practitioners' Guide Geneva, Switzerland: International Commission of Jurists.

IPCC. (2010). IPCC Independent Investigation: Greater Manchester Police contact with Clare Wood prior to her death. Independent Police Complaints Commission.

IPCC. (2012a). Christine and Shania Chambers (deceased): Independent Investigation Summary Report. Independent Police Complaints Commission.

IPCC. (2012b). Investigation into Essex Police's contact with Mrs Jeanette Goodwin prior to her death: Independent Investigation Final Report. Independent Police Complaints Commission.

IPCC. (2013a). Investigation into Greater Manchester Police contact with Ms (redacted) and Ms Katherine Cullen: Independent Investigation Final Report. Independent Police Complaints Commission.

IPCC. (2013b). Maria Stubbings (Deceased) Investigation concerning the actions of Essex Police in 2008: Independent Investigation Final Report. Independent Police Complaints Commission. 
IPCC. (2014). Investigation into the contact between Merseyside Police and Becky McPhee prior to her murder on 5 January 2012: Independent Investigation Final Report. Independent Police Complaints Commission.

Jacob, S. 2017. Strengthening the Collective Response: Safeguarding Victims, Reducing Risk and Securing Justice. 9th Annual Domestic Violence Symposium: Safeguarding Victims, Reducing Risk and Changing Norms. London: Public Policy Exchange.

Johnson, M. P. 2008. A Typology of Domestic Violence: Intimate Terrorism, Violent Resistance, and Situational Couple Violence. Lebanon, NH: Northeastern University Press.

Karakurt, G., Smith, D., and Whiting, J. (2014). "Impact of intimate partner violence on women's mental health." Journal of Family Violence, 29(7), 693-702.

Kelly, L. (2005). "How violence is constitutive of women's inequality and the implications for equalities work"Equality and Diversity Forum Seminar. City: London.

Kitzinger, C., Brant, C., and Too, Y. L. (1994). "Anti-lesbian harassment", in C. Brant and Y. L. Too, (eds.), Rethinking Sexual Harassment. London: Pluto Press.

Kristeva, J. (1982). Powers of Horror: An Essay on Abjection, New York: Columbia University Press.

Lipsky, M. (1980). Street-Level Bureaucracy: Dilemmas of the Individual in Public Services, New York: Sage.

Litherland, R. (2012). "The health visitor's role in the identification of domestic abuse." Community Practitioner: The Journal Of The Community Practitioners' \& Health Visitors' Association, 85(8), 20-23.

Lehrner, A. \& Allen, N. E. 2009. Still a movement after all these years? Current tensions in the domestic violence movement. Violence Against Women, 15, 656-677.

Littlechild, B. (2008). "Child Protection Social Work: Risks of Fears and Fears of Risks - Impossible Tasks from Impossible Goals?" Social Policy \& Administration, 42(6), 662-675.

Maxwell, N., Scourfield, J., Featherstone, B., Holland, S., and Tolman, R. (2012). "Engaging fathers in child welfare services: a narrative review of recent research evidence." Child \& Family Social Work, 17(2), 160-169 10p.

McDonald, J. 2005. Neo-liberalism and the pathologising of public issues: The displacement of feminist service models in domestic violence support services. Australian Social Work, 58, 275-284.

Newton, J. (2002). "Barriers to effective quality management and leadership: Case study of two academic departments." Higher Education, 44(2), 185-212.

NICE 2016. Domestic Violence and Abuse: Quality Standard. London: National Institute for Health and Care Excellence.

Oakley, A. (1981). "Interviewing women: A contradiction in terms", in H. Roberts, (ed.), Doing Feminist Research. London: Routledge, pp. 30-61.

On Track. (2017). Understanding Domestic Abuse: Findings from On Track. Women's Aid Federation of England, London.

Oram, S., Trevillion, K., Feder, G., and Howard, L. M. (2013). "Prevalence of experiences of domestic violence among psychiatric patients: Systematic review." The British Journal of Psychiatry, 202(2), 94-99.

Scourfield, P. (2015). "Even Further beyond Street-Level Bureaucracy: The Dispersal of Discretion Exercised in Decisions Made in Older People's Care Home Reviews." British Journal of Social Work, 45(3), 914-931.

Silverman, D. (2013). Doing Qualitative Research (Fourth Edition), London: Sage.

Skomorovsky, A., Hujaleh, F., and Wolejszo, S. (2015). "Intimate Partner Violence in the Canadian Armed Forces: The Role of Family Stress and Its Impact on Well-Being." Military Medicine, 180(7), 809-816.

Spangaro, J., Poulos, R. G., and Zwi, A. B. (2011). "Pandora Doesn't Live Here Anymore: Normalization of Screening for Intimate Partner Violence in Australian Antenatal, Mental Health, and Substance Abuse Services." Violence \& Victims, 26(1), 130-144. 
Stanley, N. (1997). "Domestic violence and child abuse: Developing social work practice." Child \& Family Social Work, 2(3), 135-145.

Stockman, J. K., Hayashi, H., and Campbell, J. C. (2015). "Intimate partner violence and its health impact on disproportionately affected populations, including minorities and impoverished groups." Journal of Women's Health, 24(1), 62-79.

Taylor, D. (2011). "Police to target domestic abuse among older couples"The Guardian. City: Guardian Media Group: London.

Taylor, I. (2007). "Discretion and Control in Education: The Teacher as Street-level Bureaucrat." Educational Management Administration \& Leadership, 35(4), 555-572.

Thiara, R., K., Hague, G., Bashall, R., Ellis, B., and Mullender, A. (2012). Disabled Women and Domestic Violence: Responding to the Experiences of Survivors, London: Jessica Kingsley.

Tummers, L. L. G., Bekkers, V., Vink, E., and Musheno, M. (2015). "Coping During Public Service Delivery: A Conceptualization and Systematic Review of the Literature." Journal of Public Administration Research \& Theory, 25(4), 1099-1126.

WAFE. 2017. Change that Lasts [Online]. Women's Aid Federation of England. Available: https://www.womensaid.org.uk/our-approach-change-that-lasts/ [Accessed 14 May 2018].

Walby, S. (2009). The Cost of Domestic Violence: Up-date 2009, Lancaster: Lancaster University.

Walby, S., and Allen, J. (2004). Domestic Violence, Sexual Assault and Stalking: Findings from the British Crime Survey. Home Office, London.

Warrington, M. 2003. Fleeing from fear: The changing role of refugees in meeting the needs of women leaving violent partners. Capital \& Class, 27, 123-150.

Whiting, N. (2013). "Effecting Operational Change Through Training: Challenges and Approaches", in N. Lombard and L. McMillan, (eds.), Violence Against Women: Current Theory and Practice in Domestic Abuse, Sexual Violence and Exploitation. London: Jessica Kingsley.

Williams, C., Larsen, U., and McCloskey, L. A. (2010). "The impact of childhood sexual abuse and intimate partner violence on sexually transmitted infections." Violence \& Victims, 25(6), 787798.

Wittenberg, E., Joshi, M., Thomas, K. A., and McCloskey, L. A. (2007). "Measuring the effect of intimate partner violence on health-relatedquality of life: a qualitative focus group study." Health \& Quality of Life Outcomes, 5, 67-73.

Wong, J., and Mellor, D. (2014). "Intimate partner violence and women's health and wellbeing: Impacts, risk factors and responses." Contemporary Nurse: A Journal for the Australian Nursing Profession, 46(2), 170-179.

Wooditch, A., Duhaime, L., and Meyer, K. (2016). "Street-level Discretion and Organizational Effectiveness in Probation Services." Federal Probation, 80(1), 39-44.

Zang, X. (2016). "Research on Street-Level Discretion in the West: Past, Present, and the Future." Chinese Political Science Review, 1(4), 610-622. 